\title{
Strain Differentiation of Rothia dentocariosa and Related Isolates by Sodium Dodecyl Sulfate-Polyacrylamide Gel Electrophoresis
}

\author{
PETE G. FOTOS, ${ }^{*}$ MARY A. GERENCSER, AND DAVID B. YELTON \\ Department of Medical Microbiology, West Virginia University Medical Center, Morgantown, West Virginia 26506
}

Sodium dodecyl sulfate-polyacrylamide slab gel electrophoresis was used to compare soluble protein fractions from 36 strains of Rothia dentocariosa and related bacteria. The resulting protein patterns were examined to identify the bands of major and minor frequency within the genus. A cluster analysis revealed three major Rothia groups and a fourth group representing the genus Actinomyces. Our data demonstrated good correlations $(>70 \%)$ with existing biotyping and serotyping schemes of these isolates. We suggest that electrophoretic group 2 represents a new Rothia species.

The genus Rothia was created by Georg and Brown (4) to accommodate aerobic, catalase-positive actinomycetes which did not fit into either Actinomyces or Nocardia. This genus contains one species, Rothia dentocariosa. Since its conception, numerous strains have been isolated from oropharynges, dental plaque, and, occasionally, infectious processes $(2,8,11,16)$. A number of isolates of Rothia-like bacteria which are biochemically or serologically different than $R$. dentocariosa have been encountered. The taxonomic status of these Rothia-like organisms is uncertain.

A number of investigators $(3,6,12,13)$ have shown that polyacrylamide gel electrophoresis (PAGE) of soluble proteins can be used to differentiate species of bacteria. Taxonomic groupings based on PAGE of proteins agree closely with groupings based on deoxyribonucleic acid-deoxyribonucleic acid homology $(1,10,14)$. Therefore, PAGE of soluble proteins can be a useful and reliable taxonomic tool.

In this study, sodium dodecyl sulfate-PAGE was used in an attempt to resolve some of the taxonomic uncertainty associated with strains of $R$. dentocariosa and Rothia-like organisms. In addition, several representatives of the genus Actinomyces were examined. The electrophoretic patterns obtained were used to measure strain similarity among the Rothia isolates and to demonstrate differences between Rothia and Actinomyces species.

\section{MATERIALS AND METHODS}

Organisms and growth conditions. The Rothia and Rothialike strains used in this study are listed in Table 1. Stock cultures were maintained on Trypticase-soy agar (BBL Microbiology Systems, Cockeysville, Md.) slants and were transferred monthly. For electrophoresis, cultures were grown aerobically at $35^{\circ} \mathrm{C}$ in 1 liter of Trypticase-soy broth (BBL) in 2-liter flasks on a shaker; these cultures were harvested at mid-log phase (determined spectrophotometrically) by centrifugation.

Sample preparation. After harvesting, the cells from each culture were washed twice in chilled tris-(hydroxymethyl)aminomethane buffer (Sigma Chemical Co., St. Louis, Mo.), $\mathrm{pH}$ 8.9. Approximately $30.0 \mathrm{ml}$ of washed, packed cells was combined with $20.0 \mathrm{ml}$ of glass beads (diameter, $0.1 \mathrm{~mm}$ ) and disrupted with a Braun homogenizer (Glasperlen; Melsungen $\mathrm{AG}$, West Germany) maintained at $4^{\circ} \mathrm{C}$. The resulting homogenates were then centrifuged at $3,000 \times g$ to remove the beads and any remaining whole cells. The supernatants were

\footnotetext{
* Corresponding author.
}

centrifuged at $38,000 \times g$ for $1 \mathrm{~h}$ to yield the soluble fractions.

The supernatants from the high-speed centrifugation were

TABLE 1. Strains used in this study

\begin{tabular}{|c|c|c|}
\hline Organism & $\begin{array}{l}\text { WVU } \\
\text { strain } \\
\text { no. }{ }^{a}\end{array}$ & Other designation and/or source ${ }^{a}$ \\
\hline \multirow{18}{*}{$R$. dentocariosa } & 477 & CDC W808, leg stump drainage \\
\hline & 478 & CDC W876, blood \\
\hline & 858 & WVU isolate, dental plaque \\
\hline & 1200 & WVU isolate, dental plaque \\
\hline & $1489^{\mathrm{T}}$ & ATCC $17931^{\mathrm{T}}$ (neotype strain) \\
\hline & 1524 & ATCC 14189, carious teeth \\
\hline & 1525 & ATCC 14190 , carious teeth \\
\hline & 1526 & ATCC 14191 , carious teeth \\
\hline & 1534 & CDC W1581 \\
\hline & 1549 & CDC W1578, sputum \\
\hline & 1555 & CDC X359 \\
\hline & 1603 & CDC X347 \\
\hline & $1604^{\mathrm{T}}$ & ATCC $17931^{\mathrm{T}}$ (neotype strain) \\
\hline & 1605 & $\begin{array}{l}\text { ATCC } 19426, \text { type strain of } \\
\text { Nocardia salivae } b\end{array}$ \\
\hline & 1610 & CDC W3324, urine \\
\hline & 1611 & CDC D7154, abdominal wound \\
\hline & 1612 & CDC E4554, salivary gland drainage \\
\hline & 1613 & CDC W585 \\
\hline \multirow[t]{8}{*}{ Rothia-like strains } & 841 & WVU isolate, dental plaque \\
\hline & 918 & WVU isolate, dental plaque \\
\hline & 936 & WVU isolate, dental plaque \\
\hline & 972 & WVU isolate, dental plaque \\
\hline & 997 & WVU isolate, dental plaque \\
\hline & 1073 & WVU isolate, dental plaque \\
\hline & 1556 & CDC X483, blood \\
\hline & 1557 & CDC W781, throat \\
\hline Actinomyces israelii & $46^{\mathrm{T}}$ & ATCC $12102^{\mathrm{T}}$ (neotype strain) \\
\hline Actinomyces & 45 & ATCC 12104 , reference strain \\
\hline \multirow[t]{2}{*}{ naeslundii } & 777 & S. Socransky strain I \\
\hline & 820 & S. Bellack N16, dental plaque \\
\hline Actinomyces & 371 & ATCC 19246 , human actinomyces \\
\hline \multirow{2}{*}{ viscosus } & 626 & C. S. Cumins, VPI 3426 \\
\hline & $745^{\mathrm{T}}$ & ATCC $15987^{\mathrm{T}}$ \\
\hline \multirow{3}{*}{$\begin{array}{l}\text { Actinomyces } \\
\text { odontolyticus } \\
\text { Actinomyces bovis }\end{array}$} & 482 & WVU isolate, dental plaque \\
\hline & 750 & CDC W1043 \\
\hline & $116^{\mathrm{T}}$ & ATCC $13683^{\mathrm{T}}$ (neotype strain) \\
\hline
\end{tabular}

${ }^{a}$ WVU, West Virginia University Culture Collection, Morgantown; CDC, Centers for Disease Control, Atlanta, Ga.; ATCC, American Type Culture Collection, Rockville, Md.; VPI, Virginia Polytechnic Institute and State University, Blacksburg.

${ }^{b}$ Originally described as the type strain of Nocardia salivae. $N$. salivae is a synonym of $R$. dentocariosa. 
adjusted to a concentration of $1,000 \mu \mathrm{g}$ of protein per $\mathrm{ml}$ (Bradford protein assay) with buffer, divided into portions, labeled, and stored at $-70^{\circ} \mathrm{C}$.

Electrophoresis. Sodium dodecyl sulfate-PAGE was carried out in a vertical slab system (Protean 16-cm cell; BioRad Laboratories, Richmond, Calif.). A discontinuous buffer system with a $5 \%$ stacking gel and a $10 \%$ resolving gel $(\mathrm{pH}$ 6.7 and 8.9 , respectively) was used (9). A $50-\mu 1$ portion of each microbial fraction was added to an equal amount of sample buffer [50\% glycerol, 2\% 2-mercaptoethanol, $1 \%$ sodium dodecyl sulfate, $0.125 \mathrm{M}$ tris(hydroxymethyl)aminomethane ( $\mathrm{pH} 6.7), 0.01 \%$ bromophenol blue], preheated for 1 $\min$ at $100^{\circ} \mathrm{C}$, and layered onto the superior gel interface in separate wells. Since repeat runs were used to enhance clarity and to assure reproducibility, $R$. dentocariosa WVU $1604^{\mathrm{T}}(\mathrm{T}=$ type strain $)$ and bovine serum albumin were included in each electrophoretic run.
Constant application of $150 \mathrm{~V}$ (model 500/200 power supply; Bio-Rad) for $4 \mathrm{~h}$ resulted in a dye front migration of about $7.5 \mathrm{~cm}$. The chamber buffer was maintained at a temperature of $10^{\circ} \mathrm{C}$

The gels were stained for $2 \mathrm{~h}$ in $50 \%$ methanol-7\% acetic acid-1\% (wt/vol) Coomassie blue R-250 (Bio-Rad); this was followed by a $24-\mathrm{h}$ destaining period in $5 \%$ glacial acetic acid with stirring in a diffusion destainer (model 22; Bio-Rad).

Data analysis. The resulting slab gels were photographed, and the protein band migration distances were measured and compared from the photographs. The band migration distances were divided by the migration distance of bovine serum albumin, which yielded relative distance values. This served to normalize banding patterns, allowing inter- and intrarun comparisons. A composite of all 36 strains was compiled on a cue sheet for conversion to a binary code, with 1 denoting presence and 0 denoting absence of a band

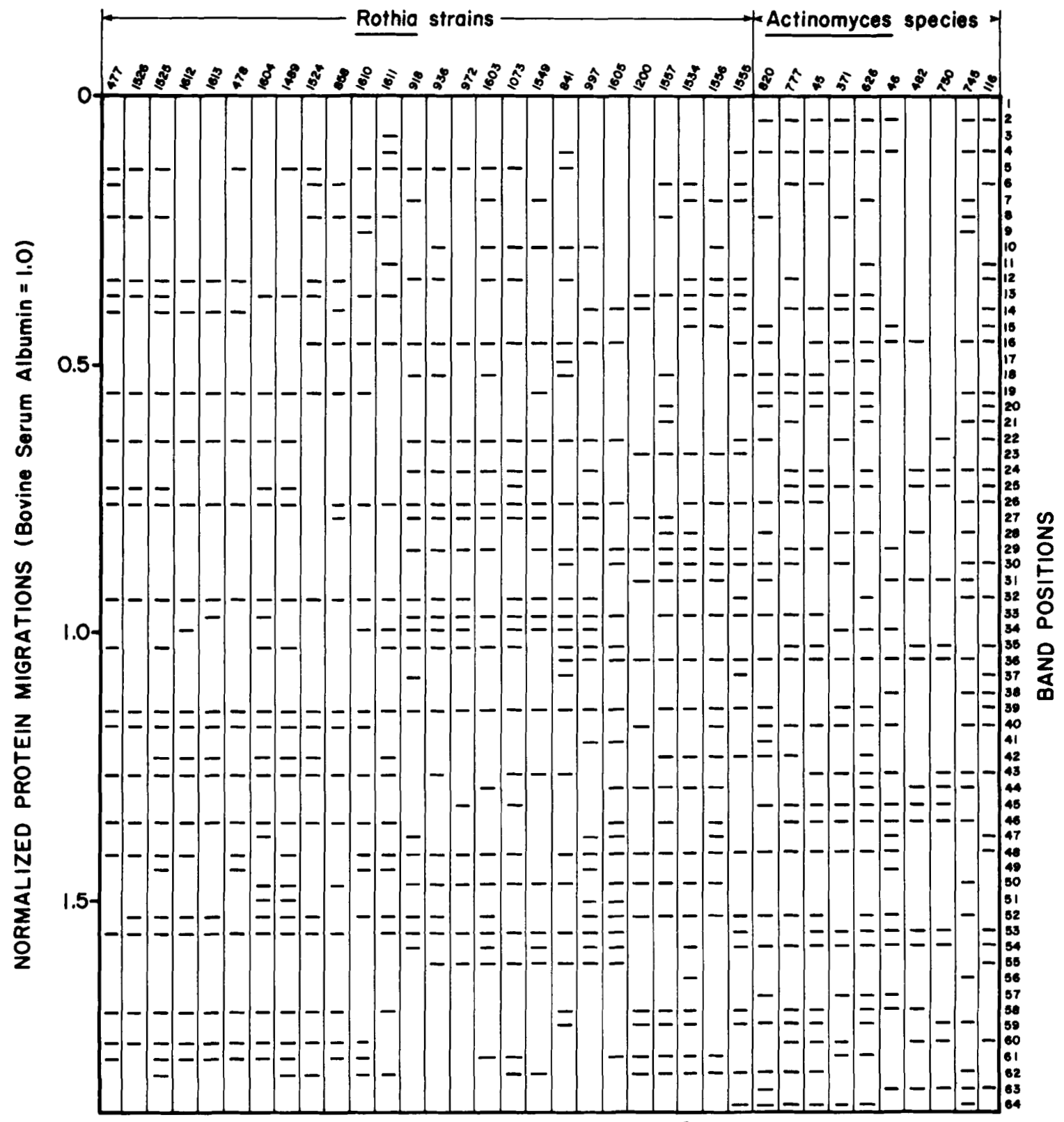

FIG. 1. Normalized electrophoretic banding patterns for 10 Actinomyces and 26 Rothia strains. 


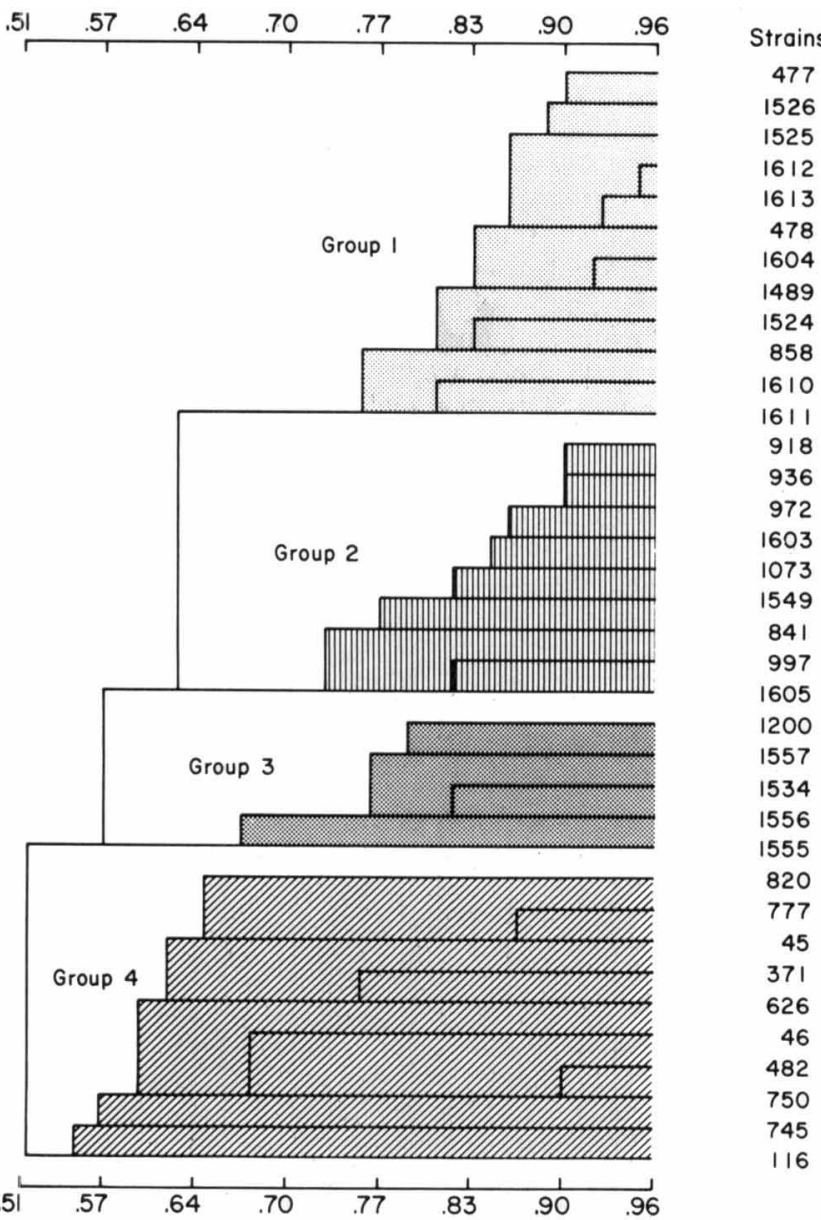

FIG. 2. Phenogram of relationships among various Rothia and Actinomyces strains clustered by unweighted pair group averaging. The scale represents similarity (simple matching) coefficients.

for computer programming. The similarity coefficient was based on simple matching and incorporated a rectangular 36$\times-64$ matrix with unweighted pair group analysis, using arithmetic averages (5). This resulted in the clustering of the 36 strains in decreasing order of similarity with respect to the 64 possible band positions for each strain.

\section{RESULTS AND DISCUSSION}

The normalized electrophoretic patterns obtained for Rothia and Actinomyces proteins are shown in Figure 1.

The Rothia strains demonstrated a common genus band at position 39, with one exception (strain WVU 1200). Bands at positions $26,32,48$, and 53 occurred in at least 20 of the 26 Rothia strains tested. Other bands that appeared in 16 of the 26 Rothia strains included the bands at positions $12,22,43$, 52,58 , and 61 .

Although no common band was observed in the 10 strains of Actinomyces examined, band 36 was found in all strains except the Actinomyces bovis strain, and band 54 appeared in all strains except Actinomyces viscosus serotype 1 (strain WVU $745^{\mathrm{T}}$ ). Other bands evident in 8 of the 10 strains included the bands at positions $2,4,16,35,40$, and 45 . In 7 of the 10 Actinomyces strains studied, bands were observed at positions $19,24,25,43,48$, and 53 .

A cluster analysis of the protein band patterns identified four major groups (Fig. 2). Cluster 4 contained all Actinomyces strains, which were clearly separable from the Rothia strains (clusters 1, 2, and 3) at a similarity level of 52\%. Since the number of strains examined was limited, no additional conclusions about relationships within the genus Actinomyces were reached. However, it should be noted that one strain of A. viscosus serotype 1 ( strain WVU $745^{\mathrm{T}}$ ) did show some relationship to two strains of serotype 2 (strains WVU 371 and WVU 626); similarity coefficients, 65 and $67 \%$, respectively). A. viscosus WVU 371 and WVU 626 were more closely related (similarity level, $76 \%$ ).

The largest Rothia group, cluster 1, contained 11 strains. The levels of similarity within this cluster ranged from 76 to 95\%. Strains WVU 1489 and WVU 1604 are duplicate representatives of the type strain of $R$. dentocariosa, strain ATCC 17931. These strains showed a similarity coefficient of $92 \%$. Because the type strain is a member of cluster 1 , we believe that this cluster represents the species $R$. dentocariosa.

Lesher et al. (7) divided Rothia into four biotypes and three serotypes. Figure 3 shows the relationship of these biotypes and serotypes to the PAGE data for those strains which demonstrated similarity levels of $75 \%$ or more. All cluster 1 strains belong to biotype 1 but fall into serotypes 1 and 2. This suggests that $R$. dentocariosa is homogeneous biochemically but has more than one serotype. On the other hand, a comparison of these data with the numerical taxonomic data of Schofield and Schaal (15) indicates that there is also biochemical variation in $R$. dentocariosa. Schofield and Schaal identified two subclusters in the genus Rothia on the basis of morphological and physiological characters. Two strains belonging to subcluster $16 \mathrm{a}$ and one strain belonging to subcluster $16 \mathrm{~b}$ were used in our study. All three strains belonged to sodium dodecyl sulfate-PAGE cluster 1.

The second Rothia cluster, cluster 2, contained nine strains; the intracluster levels of similarity ranged from 75 to $90 \%$. Cluster 2 was related to cluster 1 at a level of $63 \%$. Cluster 2 strains belong primarily to biotypes 3 and 4 , which are biochemically different from typical $R$. dentocariosa. Serologically, five of the strains belong to serotype 3 , three strains belong to serotype 1 , and one strain remains untyped. Further study of the strains that are now placed in serotype 1 may show that they are actually different from serotype 1 strains. This has been done for strain WVU 1603, which was originally identified as serotype 1 . Reciprocal absorption studies have indicated that this strain has a strong crossreaction with, but is different from, serotype 1 strains (unpublished data). On the basis of biochemical and serological reactions, strain WVU 1603 was thought to resemble strain WVU 1604. The results of the PAGE studies showed that these strains are different.

Since taxonomic groupings based on electrophoresis of proteins closely resemble groupings based on deoxyribonucleic acid-deoxyribonucleic acid homology studies, we suggest that PAGE cluster 2 represents a second species of the genus Rothia.

The third and smallest Rothia cluster contained only five strains. Cluster 3 had lower levels of intracluster similarity than the other Rothia clusters. The levels of similarity within cluster 3 ranged from 63 to $82 \%$. Cluster 3 strains were only $58 \%$ related to cluster 1 and 2 strains. Cluster 3 strains also exhibited heterogeneity in biochemical and serological reactions. Serologically, one strain, strain WVU 1200, was identified as serotype 2 , and one additional strain crossreacted with both serotype 1 and serotype 2 strains. The remaining three strains did not react with the available 

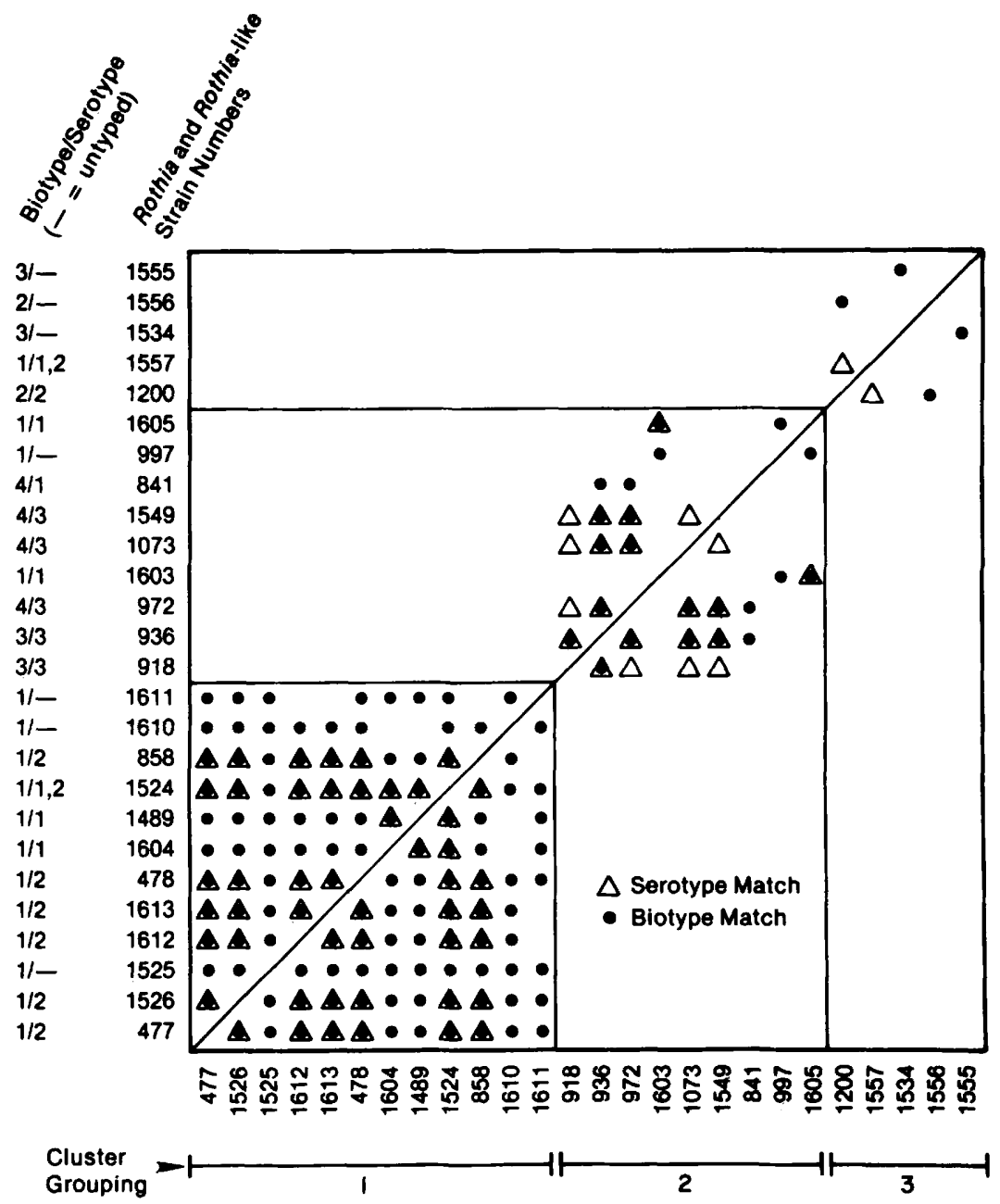

FIG. 3. Biotype and serotype matches in Rothia strains with PAGE similarity coefficients of $75 \%$ or greater. (Biotypes and serotypes were determined by Lesher et al. [7].)

antisera. This cluster is too small and diverse to make any suggestions concerning its species status at the present time.

\section{ACKNOWLEDGMENTS}

We are grateful to Susan McCormick for preparing the Actinomyces cell homogenates.

This research was supported by grant 7700142 from the West Virginia University Dental Corporation.

\section{LITERATURE CITED}

1. Biavati, B., V. Scardovi, and W. E. C. Moore. 1982. Electrophoretic patterns of proteins in the genus Bifidobacterium and proposal of four new species. Int. J. Syst. Bacteriol. 32:358-373.

2. Brown, J. M., L. K. Georg, and L. C. Waters. 1969. Laboratory identification of Rothia dentocariosa and its occurrence in human clinical materials. Appl. Microbiol. 17:150-156.

3. El-Sharkawy, T. A., and D. Huisingh. 1971. Differentiation among Xanthomonas species by polyacrylamide gel electrophoresis of soluble proteins. J. Gen. Microbiol. 68:155-165.

4. Georg, L. K., and J. M. Brown. 1967. Rothia, gen. nov. An aerobic genus of the family Actinomycetaceae. Int. J. Syst. Bacteriol. 17:79-88.

5. Harner, J. E. 1980 . Numerical taxonomy system of multivariate statistics. Department of Statistics and Computer Science, West Virginia University, Morgantown.

6. Kersters, K., and J. De Ley. 1975. Identification and grouping of bacteria by numerical analysis of their electrophoretic protein patterns. J. Gen. Microbiol. 87:333-342.

7. Lesher, R. J., M. A. Gerencser, and V. F. Gerencser. 1974. Morphological, biochemical and serological characterization of Rothia dentocariosa. Int. J. Syst. Bacteriol. 24:154-159.

8. Lutwick, L. I., and R. C. Rockhill. 1978. Abscess associated with Rothia dentocariosa. J. Clin. Microbiol. 6:612-613.

9. Maizel, J. V. 1971. Polyacrylamide gel electrophoresis of viral proteins, p. 179-215. In K. Maramorosch and H. Koprowski (ed.), Methods of virology, vol. 5. Academic Press, Inc., London.

10. Moore, W. E. C., D. E. Hash, L. V. Holdeman, and E. P. Cato. 1980. Polyacrylamide slab gel electrophoresis of soluble proteins for studies of bacterial floras. Appl. Environ. Microbiol. 39:900-907

11. Pope, J., C. Singer, T. E. Kiehn, B. J. Lee, and D. Armstrong. 1979. Infective endocarditis caused by Rothia dentocariosa. Ann. Intern. Med. 91:746-747.

12. Roberts, G. P., W. T. Leps, L. E. Silver, and W. J. Brill. 1980. Use of two-dimensional polyacrylamide gel electrophoresis to identify and classify Rhizobium strains. Appl. Environ. Microbiol. 39:414-422

13. Roberts, R. C., D. P. Zais, J. J. Marx, and M. W. Treuhaft. 1977. Comparative electrophoresis of the protein and proteases in thermophilic actinomycetes. J. Lab. Clin. Med. 90:10761084 .

14. Russell, R. R. B. 1976. Classification of Streptococcus mutans 
strains by SDS gel electrophoresis. Microbios Lett. 2:55-59.

15. Schofield, G. M., and K. P. Schaal. 1981. A numerical taxonom-

ic study of members of the Actinomycetaceae and related taxa.

J. Gen. Microbiol. 127:237-259.
16. Takamori, K., F. Mizuno, N. Takahashi, and T. Horikawa. 1978. Distribution of Neisseria, Rothia, and streptococci in early stages of dental plaque. Bull. Tokyo Med.-Dent. Univ. 25:189196. 